\title{
Rietveld quantitative phase analysis with Molybdenum radiation
}

Ana Cuesta ${ }^{\mathrm{a}}$, Gema Álvarez-Pinazo a , Marta García-Matéa , Isabel Santacruz ${ }^{\mathrm{a}}$, Miguel A.G. Aranda ${ }^{\mathrm{a}, \mathrm{b}}$, Ángeles G. De la Torre ${ }^{\mathrm{a}}$, Laura León-Reina ${ }^{\mathrm{c}, *}$.

a Departamento de Química Inorgánica, Universidad de Málaga, Campus Teatinos S/N. 29071-Málaga, Spain.

b ALBA-CELLS synchrotron, Carretera BP 1413, Km. 3.3, E-08290 Cerdanyola, Barcelona, Spain.

c Servicios Centrales de Investigación SCAI, Universidad de Málaga, 29071Málaga, Spain

Abstract Building materials are very complex samples of worldwide importance, hence quantitative knowledge of their mineralogical composition is necessary to predict performances. Rietveld quantitative phase analysis (RQPA) allows a direct measurement of the crystalline phase contents of cements. We highlight in this paper the use of laboratory x-ray powder diffraction (LXRPD) employing high energy radiation, Mo, for attaining the RQPA of cements. Firstly, we evaluate the accuracy of RQPA employing a commercial calcium sulfoaluminate clinker with gypsum. In addition to Mo $K \alpha_{1}$ and Mo $K \alpha_{1,2}$ radiations, $\mathrm{Cu}$ and synchrotron patterns are also analyzed for the sake of comparison. Secondly, the assessment of the accuracy of RQPA results obtained using different radiations (synchrotron, $\mathrm{Mo}$ and $\mathrm{Cu}$ ) and geometries (reflection and transmission) is performed by analyzing two well known commercial samples. As expected, for LXRPD data, accuracy in the RQPA results improves as the irradiated volume increases. Finally, three very complex aged hydrated cements have been analyzed using MoK $\alpha_{1}$-LXRPD and Synchrotron-XRPD. The main overall outcome of this work is the benefit for RQPA of using strictly monochromatic Mo $K \alpha_{1}$ radiation. Best laboratory results arise from Mo $K \alpha_{1}$ data as the effective tested volume is much increased but peak overlapping is not swelled.

\section{Key words:}

Mo and Cu radiations, Synchrotron radiation, irradiated volume, cement, accuracy. 


\section{INTRODUCTION}

In a standard laboratory instrument, the X-rays are produced in a sealed-tube source, in the same way as they were produced in the original tube discovered by W. C. Rontgen in 1895, where electrons accelerated by a potential difference of up to $60 \mathrm{kV}$ bombard a metal anode inside a vacuum tube. Such sources differ only in the intensity of the radiation produced. The most common target elements are $\mathrm{Cu}$ for powder diffraction and Mo for single crystal studies. Alternative radiations, both with lower ( $\mathrm{Cr}, \mathrm{Fe}$ and Co) and higher (Ag and W) energies, are employed for very special applications. For routine powder diffraction work, a $\mathrm{Cu}$ tube is the most common choice, giving the wavelength 1.5406 A. Heavier elements are believed to give too short wavelengths for most practical use in the laboratory, as they exacerbate the peak overlapping, though they become important for total scattering, pair distribution function (PDF) studies and in order to avoid fluorescence from samples containing elements excited by $\mathrm{Cu}$ radiation (Dinnebier and Billinge, 2008). On the other hand, the advantages of highenergy penetrating laboratory X-ray sources are i) larger irradiated volumes, ii) lower absorption effects, and iii) more accessible Bragg reflections. However, to keep the angular resolution in powder diffraction is a key point since high-energy patterns are squeezed and therefore, if the appropriate optic elements are not present, peak overlap may become an important drawback.

For powder diffraction-based quantitative phase analysis procedures, it is generally accepted that the peak intensities need to be measured to an accuracy of about $\pm 1-2 \%$ relative (Dinnebier and Billinge, 2008). The ability to achieve this goal is strongly influenced by the size of the crystallites in the sample and their number contributing to the Debye-Scherrer cone (Smith, 2001). Reproducible diffraction intensities in 0D or 1D detectors require smooth cones which are obtained from samples containing small 
crystallite size(s) and high-enough number of crystallites per phase. Elton and Salt (1996) estimated the number of crystallites diffracting in a sample. Fluctuations in peak intensity between replicate samples arise largely from statistical variation in the number of particles contributing to the diffraction process. It was shown that small changes to the instrumental and sample configurations can significantly improve the sample particle statistics. For a given sample, several methods can be used to increase the number of crystallites contributing to the diffraction pattern, including: i) rotate the sample about the normal to the sample surface for a flat plate sample or the sample axis for a capillary sample; ii) oscillate the sample about the incident angle axis, this motion removes the exact Bragg-Brentano theta/2theta relationship between sample and receiving slit and may lead to aberrations in the peak intensities; iii) repack the sample, recollect and reanalyze the diffraction data, averaging the results from each analysis will produce more meaningful parameter values, iv) reduce the average crystallite size(s) by milling (Buhrke et al., 1998), however, caution must be exercised in the choice of mill since many grinding techniques introduce peak broadening and some phases can undergo solid-solid phase transitions or dehydration during grinding (Hill and Madsen, 2002); and v) enhancing particle statistic by the increasing the diffracting volume. X-ray powder diffraction only concerns a 'small' volume of the material, called the irradiated volume, which is determined by the product of the irradiated surface and effective depth. Swapping $\mathrm{Cu}$ by Mo radiation, it is possible to deeply penetrate the sample enhancing the irradiated volume which has been employed in gem characterization where the sample cannot be altered (León-Reina et al., 2011). This approach also allows its combination with others listed above in order to maximize the number of crystallites diffracting in a sample. 
On the other hand, there is no doubt that Rietveld quantitative phase analysis (RQPA) is one of the most important uses of powder diffraction for analyzing materials, in general (Madsen et al., 2001; Scarlett et al., 2002), and in cements in particular (De la Torre and Aranda, 2003). There are several interlaboratory comparisons that gave some key recommendations for carrying out accurate RQPA and included results relating to the influence of sample related effects such as preferred orientation and microabsorption (Madsen et al., 2001; Scarlett et al., 2002; Stutzman, 2005). Cements are an archetype in RQPA due to is complex phase assemblage with always more than four crystalline phases and usually more than seven/eight crystalline phases for hydrating cements. Laboratory and synchrotron X-ray powder diffraction (LXRPD, SXRPD) (De la Torre and Aranda, 2003) have been thoroughly used for clinker and cements characterization. Rietveld quantitative phase analysis of cement related materials is complex for a number of reasons: (a) high number of phases and the resulting strong peak overlapping; (b) some phases, for instance, alite and gypsum, crystallize as flat plates which may show preferred orientation effects (De la Torre and Aranda, 2003; De la Torre et al., 2004); (c) phases can crystallize as several polymorphs (Dunstetter, 2006; De la Torre et al., 2002, 2008); (d) the number of illuminated crystallites may be not high enough to ensure a random orientation for all diffraction planes; (e) the atomic impurities inside each phase are not known. The mineralogical quantification of selected clinkers and cements was carried out by LXRPD and the Rietveld method employing the data from different laboratories (León-Reina et al., 2009) and allowing the determination of the precision ranges and the general uncertainties for the accuracies for anhydrous cements. Recently, two review articles have been devoted to RQPA of Portland cements (Le Saout et al., 2011) and Portland cements, blended Portland cements and their hydration products (Aranda et al., 2012). 
RQPA has been employed for a number of applications related to the hydration reactions of OPC materials (Scrivener and Nonat, 2011). The uses have been expanded from the hydration of model systems (Bellman et al., 2010) to blended cements and the role of admixtures and superplasticizers. RQPA has been used to study the hydration reactions of commercial OPC in reflection geometry with laboratory data (Scrivener et al., 2004). The results were satisfactorily compared to those obtained from thermal analysis and electron microscopy. RQPA, in transmission geometry, was employed for studying OPC hydration products (Mitchell et al., 2006). The data obtained from capillary measurements showed little preferential orientation. This study highlighted the benefits of the transmission geometry as more particles were measured which yields more reliable quantitative results. All these previous studies employed Cu-radiation. To the best of our knowledge, there are not reports dealing with RQPA with Molybdenum radiation for cements or complex samples. Complex samples are defined as those containing more than three crystalline phases.

In this article, we highlight the use of LXRPD employing Mo radiation for attaining the RQPA of cements (with selected examples: clinkers, cements and hydrating cement pastes). Firstly, we focus our attention on evaluating the accuracy of RQPA obtained from LXRPD data employing a commercial calcium sulfoaluminate 'CSA' clinker mixed with a well known quantity of crystalline gypsum. In addition to Mo $K \alpha_{1}$ and Mo $K \alpha_{1,2}$ radiations, copper and synchrotron patterns are also analyzed for the sake of comparison. Secondly, the assessment of the accuracy of RQPA results obtained using different radiations (synchrotron, $\mathrm{Mo}$ and $\mathrm{Cu}$ ) and geometries (reflection and transmission) is performed by analyzing two commercial samples, previously used in a Round Robin of building materials (León-Reina et al., 2009). Finally, and for evaluating the case for very complex materials, three aged hydrated cements have been 
analyzed using Mo $K \alpha_{1}$-LXRPD and SXRPD. The main overall outcome of this work is the benefit for RQPA of using strictly monochromatic Mo $K \alpha_{1}$ radiation.

\section{EXPERIMENTAL}

\section{A. Sample Preparation}

To ascertain the accuracy of the methodologies a commercial calcium sulfoaluminate, CSA, cement was mixed with a well known amount, 25 wt\%, of commercial micronized natural gypsum, both materials marketed in Europe by BELITH S.P.R.L. (Belgium) (García-Maté et al., 2012), hereafter labeled as 25G_CSA.

Two commercial building related materials (León-Reina et al., 2009) were used to establish the accuracy of the methodologies: i) an ordinary grey Portland clinker, labeled as GP_Clin and ii) an ordinary Portland cement type I, labeled as GP_Cem.

Three laboratory belite calcium sulfoaluminate (BCSA) (Aranda and De la Torre, 2013) cements were hydrated according to Alvarez-Pinazo et al. (2013), and after 28 days hydration was stopped and samples analyzed. Following the same nomenclature as in Alvarez-Pinazo et al. (2013), G10B0 which is a non-active BCSA with 10 wt $\%$ of gypsum and G5B2 and G10B2 which are active BCSAs with 5 and 10 wt\% of gypsum, respectively, have been used. These samples have been selected as they are very complex mixtures.

\section{B. Transmission Cu $K \alpha$ and Mo $K \alpha$ LXRPD data acquisition.}

Table I gives experimental set up details for the three diffractometers used for this type of data collection.

1) D8 ADVANCE DaVinci (Bruker AXS) diffractometer (250 mm of diameter) with Mo radiation equipped with a primary Johansson monochromator Ge (220), which gives 
a strictly monochromatic radiation $(\lambda=0.7093 \AA)$, Mo $K \alpha_{1}$. The energy dispersive linear detector LYNXEYE XE 500 $\mu$ m, specific for high energetic radiation, was used.

2) EMPYREAN diffractometer (PANalytical B.V.) with a $\theta / \theta$ goniometer (240 mm of diameter) with Mo radiation equipped with focusing mirror component used in the incident beam path which is capable of converting the divergent beam into a convergent radiation focused on the goniometer circle. The focusing mirror is able to eliminate Mo $K \beta$, yielding Mo $K \alpha_{1,2}$ radiations. Raw patterns were mathematically treated to strip Mo $K \alpha_{2}$, see below. Data were collected preserving constant volume assumption (2theta scan mode). The detector used was the silicon-based position-sensitive detector, $\mathrm{X}^{\prime}$ Celerator, it measures up to 100 times faster than with a traditional point detector, without compromising data quality.

3) EMPYREAN diffractometer (PANalytical B.V.) with a $\theta / \theta$ goniometer ( $240 \mathrm{~mm}$ of diameter) with $\mathrm{Cu}$ radiation equipped with focusing mirror, operating as described just above, yielding $\mathrm{Cu} K \alpha_{1,2}$ radiations. The geometrical configuration of this diffractometer gives a maximum angle of measurement of $40^{\circ}$, which is low for $\mathrm{Cu}$ radiation. Consequently, constant volume assumption was not preserved during data collection (gonio scan mode). The photon counting x-ray detector, PIXCEL 3D, was used. This detector can operate in $1 \mathrm{D}$ mode offering a very small strip size and extremely high dynamic range and low noise.

The powder samples were placed (for the three diffractometers) in the holders between two Kapton foils. Table II gives details about data acquisition. Moreover, the absorption factors of each sample were experimentally measured by comparison of the direct beam with and without sample. The amount of sample loaded in the sample holders were controlled to obtain a total absorption $(\mu t \sim 1)$ which corresponds to an absorption factor of $\sim 2.7$ or $63 \%$ of direct attenuation (Cromer and Liberman, 1981). Table III gives 
linear absorption coefficients, fractional attenuation factor of the beam due to absorption (experimentally measured) as well as the calculated thickness (t) by using Lambert-Beer law and a supposed packing fraction of $75 \%$.

\section{Reflection Cu $K \alpha_{1}$ LXRPD data acquisition.}

Patterns were also recorded in Bragg-Brentano reflection geometry $(\theta / 2 \theta)$ on an X'Pert MPD PRO (PANalytical B.V.) diffractometer (240 mm of diameter) using strictly monochromatic $\mathrm{Cu} K \alpha_{1}$ radiation ( $\lambda=1.54059 \AA$ ) [Ge (111) primary monochromator]. The X-ray tube worked at $45 \mathrm{kV}$ and $40 \mathrm{~mA}$. The optics configuration was a fixed divergence slit $\left(1 / 2^{\circ}\right)$, a fixed incident antiscatter slit $\left(1^{\circ}\right)$, a fixed diffracted anti-scatter slit $\left(1 / 2^{\circ}\right)$ and $X^{\prime}$ Celerator RTMS (Real Time Multiple Strip) detector, working in scanning mode with maximum active length.

\section{Transmission synchrotron X-ray powder diffraction (SXRPD).}

SXRPD patters were collected in Debye-Scherrer (transmission) mode using the X-ray powder diffraction station of ALBA, the Spanish Synchrotron Radiation Facility (Barcelona, Spain) (Knapp et al., 2011). The wavelength, 0.62015(2) A, was selected with a double-crystal Si (111) monochromator and determined from a Si640d NIST standard (a=5.43123 $\AA$ ). The diffractometer is equipped with a MYTHEN detector system especially suited for time-resolved experiments. This detector system is not optimized for high-resolution experiments, nevertheless its suitability to perform RQPA has been previously checked (Alvarez-Pinazo et al., 2014). The capillaries of $0.7 \mathrm{~mm}$ of diameter were rotated during data collection to improve diffracting particle statistics. The data acquisition time was $\sim 25$ min per pattern to attain very good signal-to-noise ratio over the angular range $1-35^{\circ}(2 \theta)$. The temperature inside the experimental hutch was 299(1) K. 


\section{E. XRPD data analysis.}

The focusing mirror used in EMPYREAN diffractometers causes a wavelength shift of $K \alpha_{2}$ radiation. The effect is very small for copper wavelength, but it becomes noticeable for short wavelengths like molybdenum radiation. Consequently, Mo $K \alpha_{2}$ data were stripped by using the modified wide Rachinger (1948) algorithm of Delhez and Mittemeijer (1975) as implemented in HighScore+ (v. 3.0e) PANalytical software, by using $K \alpha_{2}$ shift value of $0.005, K \alpha_{2} / K \alpha_{1}$ intensity ratio of 0.6 and a wavelength ratio correction of $0 \mathrm{ppm}$.

In order to obtain RQPA, all patterns were analyzed by using the Rietveld methodology as implemented in the GSAS software package (Larson and Von Dreele, 1994). Crystal structure descriptions used for all the phases were those reported in Aranda et al. (2012). Final global optimized parameters were: background coefficients, zero-shift error, cell parameters, peak shape parameters and March-Dollase (Dollase, 1986) preferred orientation parameter, when appropriated. Peak shapes were fitted by using the pseudo-Voigt function (Thompson et al., 1987) with the asymmetry correction of Finger et al. (1994) included.

\section{RESULTS AND DISCUSSIONS}

\section{A. Characterization of peak widths.}

The instrumental contribution to peak broadening for LXRPD and SXRPD was determined with Standard Reference Material (SRM) $\mathrm{LaB}_{6}$ and $\mathrm{Na}_{2} \mathrm{Ca}_{3} \mathrm{Al}_{2} \mathrm{~F}_{14}$ (NAC) standards, respectively. Figure 1 shows measured full width at the half maximum, FWHM, as a function of angle for all the diffractometers and configurations used in this study. 
The SXRPD pattern yielded the narrowest diffraction peaks. FWHM values were $\approx 0.02^{\circ}$ (20), and not the smallest possible values $\approx 0.006^{\circ}$, as the configuration used was the MITHEN detector and not the crystal analyzer detector system. On the other hand, the broadest diffraction peaks arisen from the $\mathrm{Cu} K \alpha_{1,2}$ transmission geometry with the focusing mirror although the values ranged $0.08-0.10^{\circ}(2 \theta)$ are small enough to be considered medium-resolution data.

The most important outcome from this analysis is the observation of quite low FWHM values for strictly monochromatic Mo $K \alpha_{1}$ radiation. As depictured in Figure 1, FWHM values ranged $0.03-0.05^{\circ}(2 \theta)$. These low values implies that peak overlapping is not much important than in $\mathrm{Cu} K \alpha_{1}$ powder diffraction data.

\section{B. Comparison of irradiated volumes.}

Any analytical technique requires a representative sample or sampling. Irradiated volume in diffraction is a key issue since higher volume yields enhanced particle statistics. Therefore, the use of a high energy radiation is beneficial as the irradiated volume of sample can be increased, and absorption effects reduced. Figure 2 shows a graphical representation of the volumes that are bathed by X-ray radiations for the laboratory diffraction geometries (transmission and reflection, also included in Figure 2) used in this study.

Figures $2 \mathrm{a}$ and $2 \mathrm{~b}$ give the irradiated volumes bathed by $\mathrm{X}$-rays when using flat samples which are spun about the normal to the sample surface during data acquisition (shadowed zone) for Mo and $\mathrm{Cu}$ radiations, respectively. The total irradiated volume is calculated as $V=\pi\left(B_{w} / 2\right)^{2} t$, were $B_{w}$ stands for beam width, see Table I and it is defined by optical components on the incident beam. On the other hand, $t$ value is the thickness of the sample. These values are calculated by using Lambert-Beer law: $t=$ - 
$[\ln (1 /$ a.f. $)] / \mu \rho c$, being a.f. the experimentally determined absorption factor, $\mu$ the mass absorption coefficient in $\mathrm{cm}^{2} / \mathrm{g}, \rho$ the density in $\mathrm{g} / \mathrm{cm}^{3}$ and $\mathrm{c}$ the packing fraction, assumed to be $75 \%$ in these calculations, see Table III. Taking into account these data, irradiated volume for Mo-radiation is close to $100 \mathrm{~mm}^{3}$ while for Cu-radiation the value is not larger than $5 \mathrm{~mm}^{3}$. Unfortunately, the latter cannot be enlarged without decreasing the resolution and having strong absorption effects.

Finally, Figure 2c gives the irradiated volume for reflection geometry with Cu-radiation. In this case, the beam and slit widths are also defined by the incident beam optic components (Table I) and penetration depth $\left(\mathrm{P}_{\mathrm{D}}\right)$ has been calculated assuming an attenuation factor of 63\% (equivalent to an absorption factor of 2.7) at an incident angle of $40^{\circ}$. Sample holder is also spun about the normal to the sample surface during data collection (shadowed zone in Figure 2c), consequently the irradiated volume is close to $2 \mathrm{~mm}^{3}$ calculated as a truncated cone, $\mathrm{V}=1 / 3 \pi \mathrm{P}_{\mathrm{D}}\left[(\mathrm{D} / 2)^{2}+\left(\mathrm{B}_{\mathrm{W}} / 2\right)^{2}+(\mathrm{D} / 2)\left(\mathrm{B}_{\mathrm{W}} / 2\right)\right]$ and $\mathrm{D}=\left(\mathrm{B}_{\mathrm{W}}{ }^{2}+\mathrm{S}_{\mathrm{W}}{ }^{2}\right)^{1 / 2}$. Furthermore, the enlargement of this value is not possible as it only depends on the absorption factor of the sample.

\section{Constant volume assumption.}

As detailed in the experimental section, patterns obtained in transmission geometry with $\mathrm{Cu}$ radiation did not preserved the constant volume assumption. The intensity of the pattern was increased by a factor of $1 / \cos \theta$ as a consequence of an increase in the irradiated volume during data collection (Klug and Alexander, 1974). On the other hand, the intensity was reduced as a consequence of higher absorption by a factor of $e^{\mu t\left(1-\frac{1}{\cos \theta}\right)}$, where $\mu$ stands for the mass absorption coefficient and $t$ for the calculated thickness of the sample, both parameters given in Table III (Klug and Alexander, 1974). 
Consequently, the collected intensity should be corrected by a factor of $\frac{1}{\cos \theta} * e^{\mu t\left(1-\frac{1}{\cos \theta}\right)}$

This correction was applied to 25G_CSA and GP_Clin patterns in order to check the effect of not preserving the constant volume assumption on RQPA. Figure 3 shows raw pattern of 25G_CSA (in red) and corrected data using the correction factors given in the inset of Figure 3. An enlarged range of the high angle region of the patterns has been included as an inset to show that both patterns are almost coincident. Moreover, RQPA obtained by analyzing both raw and corrected data are included in Tables IV and V, in the $\mathrm{Cu} K \alpha_{1,2}$ column. It can be observed that results are almost the same. Consequently, in the collected angle range of this study the effect of not preserving the constant volume assumption is not significantly affecting RPQA and this correction was not applied to remaining patterns collected in transmission geometry with Cu radiation.

\section{Accuracy study.}

One of the main objectives of this work is to evaluate the accuracy of RQPA obtained from Mo K $\alpha$ LXRPD data. A comparison of the technical performances of the detectors used here are out of the scope of the present study. As discussed in the introduction, cement samples are used as a benchmark due to their complexity. So, a CSA clinker was mixed with $25 \mathrm{wt} \%$ of crystalline gypsum $\left[\mathrm{CaSO}_{4} \cdot 2 \mathrm{H}_{2} \mathrm{O}\right.$ or $\mathrm{CSH}_{2}$, in cement nomenclature $^{1}$ ], labeled as $25 \mathrm{G} \_$CSA. The accuracy of the quantitative analysis of gypsum in this sample was confirmed by comparison to the weighed value and also to the value obtained from an alternative technique DTA (Differential Thermal Analysis) and TGA (Thermo-Gravimetric Analysis) (Rajczyk and Nocun-Wczelik, 1992). Hence, the sample was heated from RT to $1273 \mathrm{~K}$ at a rate of 10 degree per minute, and its mass variation was accurately monitored. Gypsum has its own characteristic

\footnotetext{
${ }^{1}$ Cement nomenclature: $C=\mathrm{CaO}, S=\mathrm{SiO}_{2}, A=\mathrm{Al}_{2} \mathrm{O}_{3}, F=\mathrm{Fe}_{2} \mathrm{O}_{3}, \underline{S}=\mathrm{SO}_{3}, M=\mathrm{MgO}$ and $T=\mathrm{TiO}_{2}$
} 
temperature range of dehydration. By the specific mass loss at $\sim 360 \mathrm{~K}$, which corresponds to the release of two water molecules, it could be inferred the gypsum amount which was 24.96 wt\%, see Table IV.

Table IV also gives RQPA for 25G_CSA obtained by analyzing data collected by using different diffraction geometries and radiations. Strictly monochromatic Cu radiation has been used in reflection geometry $\left(\mathrm{Cu} K \alpha_{1}\right)$ while $\mathrm{Cu} K \alpha_{1,2}$ radiations were used in transmission with flat sample ( $\mathrm{Cu} K \alpha_{1,2}$ data in Table IV). Molybdenum radiation has only been used in transmission mode with flat sample with two different optic components: (i) a primary monochromator, labeled as Mo $K \alpha_{1}$ in Table IV and (ii) a focusing mirror, labeled as Mo $K \alpha_{2 \text {-strip }}$ in Table IV. Moreover, SXRPD data (labeled as synchr. $\lambda=0.62 \AA$ in Table IV) have been collected in transmission mode with the samples loaded in a capillary as described in the experimental section.

It is worth to underline than the well known weighed sample used, gypsum, is a layered compound and therefore, it usually displays preferred orientation effect. In any case, we have used this phase as it is ubiquitously used in cement field as set regulator. Furthermore, if the analyses yield good values for this extreme case, in more favorable situations the outcome could be even better. As shown in table IV, the March-Dollase preferred orientation coefficient, along [ $\left[\begin{array}{lll}0 & 1 & 0\end{array}\right]$ axis, behaved as expected. The refined value for a flat sample in reflection geometry was smaller than one, 0.73 . The refined values for flat samples in transmission geometry were larger than one ranging between 1.09 and 1.30. Finally, the SXRPD pattern collected in transmission but in a capillary did not showed preferred orientation for gypsum and so this effect was not corrected in this analysis.

High resolution SXRPD minimizes most of the experimental artifacts that may cause errors in the patterns. The value for gypsum content obtained by SXRPD was $26.1 \mathrm{wt} \%$, 
which compares very well with the added value $25.0 \mathrm{wt} \%$, see Table IV. The error is 1.1 wt\% (absolute value) or 4.6\% (relative value). Furthermore, this small discrepancy can be explained by the presence of a small amount of amorphous phase in the CSA clinker which would result in a small overestimation of the RQPA result for the added gypsum. The values obtained from Mo $K \alpha$ radiation are close to $27 \mathrm{wt} \%$ (see Table IV), about 2 wt\% (absolute error) or $10.5 \%$ and $7.4 \%$ relative errors for Mo $K \alpha_{1}$ and Mo $K \alpha_{2 \text {-strip }}$ analyses, respectively. Finally, the larger error (lower accuracy) is obtained for Curadiation patterns. The RQPA-derived gypsum contents were 28.7 and $31.0 \mathrm{wt} \%$ for $\mathrm{Cu}$ $K \alpha_{1,2}$ and $\mathrm{Cu} K \alpha_{1}$ patterns, respectively. In this case, the relative errors were as large as 14.8 and $24 \%$ (relative values). As expected, for laboratory X-ray powder diffraction data, accuracy in the RQPA results improves as the irradiated volume increases.

\section{E. Accuracy study from an inter-laboratory comparison.}

The assessment of the accuracy of RQPA results from Mo-radiation was also performed by analyzing two commercial samples, previously used in a Round Robin of building materials (León-Reina et al., 2009). Tables V and VI give RQPA of GP_Clin and GP_Cem, respectively. The first column in these tables gives the mean values and standard deviations obtained in that study (in bold) and they are considered as "true values” and they were derived from the reported values by the fourteen experienced participants. The RQPA results obtained by the radiations and geometries described in the experimental section are also given in these tables. The standard deviation reported in Tables V and VI, for the RQPA obtained in this study, are mathematically derived errors. For the sake of comparison Figure 4 gives Rietveld plots for GP_Cem collected with LXRPD with Mo and Cu radiations in transmission.

As expected, RQPA results for the SXRPD data showed the closest agreement with the reported values in the Round Robin study. In fact, the RQPA results agree within one 
standard deviation for most of the phases. Then, the next closest agreement is the Moradiation patterns with quite good agreement, see Tables V and VI. For GP_Clin sample RQPA results from Mo-K $\alpha_{1}$ radiation are almost identical to those obtained from synchrotron radiation. As the sample complexity increases, GP_Cem (Table VI), the deviation are a bit larger but still the values are quite similar.

Finally, the deviation dramatically increased in RQPA results obtained from transmission geometry with $\mathrm{Cu} K \alpha_{1,2}$ radiation. It is well known that $\mathrm{C}_{3} \mathrm{~S}$ and $\mathrm{C}_{2} \mathrm{~S}$ main peaks are severely overlapped and the use of polychromatic radiation has likely increased the correlations in data analysis. Transmission $\mathrm{Cu} K \alpha_{1,2}$ Rietveld results for both samples followed the general trend obtained in previous studies (De la Torre and Aranda, 2003; León-Reina et al., 2009), showing an underestimation of $\mathrm{C}_{3} \mathrm{~S}$ and an overestimation of $\mathrm{C}_{2} \mathrm{~S}$ respect to mean values, although total silicate content is almost constant.

The obtained values by DTA-TGA are also included in Table VI, as an alternative way to evaluate the accuracy of the obtained results. The percentages of gypsum obtained by both methods (RQPA and thermal analysis) are very similar. However, the percentages of bassanite obtained with synchrotron and Mo radiations resulted in underestimated values when compared to the DTA-TGA value. These differences could be due to the poor crystallinity of this phase which may result in a smaller content for the crystalline fraction. On the other hand, the calcite amount obtained by RQPA is slightly overestimated in the patterns collected in this study, likely due to the strong overlapping between $\mathrm{C}_{3} \mathrm{~S}$ and calcite main peaks, which makes problematic the calcite quantification at low contents.

\section{F. RQPA of very complex systems.}


Three hydrated cements have been analyzed using strictly monochromatic Mo $K \alpha_{1}$ radiation. RQPA results were crosschecked by comparison to the results from SXRPD data for the same samples. In addition to some remaining phases from the anhydrous cements, three hydrated crystalline phases are expected in these types of pastes: ettringite, stratlingite and katoite (Alvarez-Pinazo et al., 2013, 2014). Some amounts of calcium carbonate (calcite and vaterite) were also quantified. These carbonates likely arise from the carbonation of portlandite, $\mathrm{Ca}(\mathrm{OH})_{2}$, which is one of the hydration products of dicalcium silicate, a.k.a. belite. The complexity of these systems is clear from Table VII as eight crystalline phases are present. Figure 5 gives Rietveld plots for G10B0 sample (Mo $K \alpha_{1}$ and synchrotron patterns) as a representative example. Figure 5 highlights the complexity of the sample (with eight crystalline phases) but also the highresolution features the Mo $K \alpha_{1}$ pattern, where the diffraction peak overlapping is very similar to that observed in the synchrotron pattern.

Two main conclusions can be derived from the RQPA results reported in Table VII. Firstly, the carbonation effect are clearly observed in these patterns with the calcium carbonate (calcite and vaterite phases) slightly evolving with time. Secondly, and in spite of the carbonation effects and the complexity of the systems, the derived contents for the main crystalline phases agree relatively well in both studies.

\section{CONCLUSION}

Irradiated volume in diffraction is a key issue since higher volume yields enhanced particle statistics. Therefore, the use of a high energy radiation is beneficial as the irradiated volume of sample can be increased. Moreover, quite low FWHM values for strictly monochromatic Mo $K \alpha_{1}$ diffraction peaks have been measured. Low FWHM 
values indicate that peak overlapping is not much more important than in $\mathrm{Cu} K \alpha_{1}$ powder diffraction. So, the optimum results for strictly monochromatic Mo radiation arise from the large tested volumes meanwhile peak overlapping is not enlarged.

\section{ACKNOWLEDGMENTS}

This work has been supported by Junta de Andalucía through P11-FQM-7517 research grant and by Spanish MINECO through MAT2010-16213 research grant, which is cofunded by FEDER. I. Santacruz thanks a Ramón y Cajal fellowship, RYC-2008-03523. PANalytical B.V. (Almelo, The Netherland) and Bruker (Karlsruhe, Germany) are thanked by providing the Mo-radiation diffractometers. ALBA is thanked for providing synchrotron beamtime at BL04-MSPD beamline.

\section{References}

Alvarez-Pinazo, G., Santacruz, I., León-Reina, L., Aranda, M. A. G., and De la Torre, A. G. (2013). "Hydration reactions and mechanical strength developments of iron-rich sulfobelite eco-cements,” Ind. Eng. Chem. Res. 52, 16606-16614.

Alvarez-Pinazo, G., Cuesta, A., García-Maté, M., Santacruz, I., Losilla, E. R., Sanfélix, S. G., Fauth, F., Aranda, M. A. G. and De la Torre, A. G., (2014). "In-situ earlyage hydration study of sulfobelite cements by synchrotron powder diffraction,” Cem. Concr. Res. 56, 12-19.

Aranda, M. A. G. and De la Torre, A. G. (2013) Sulfoaluminate cement, in PachecoTorgal, F., Jalali, S., Labrincha, J., John, V. M. (Eds.), Eco-efficient concrete, Woodhead Publishing Limited, Cambridge, pp. 488-522. 
Aranda, M. A. G., De la Torre, A. G. and León-Reina, L. (2012). "Rietveld quantitative phase analysis of OPC clinkers, cements and hydration products,” Rev. Mineral. Geochem. 74, 169-209.

Bellmann, F., Damidot, D., Moser, B. and Skibsted, J. (2010). “Improved evidence for the existence of intermediate phase during hydration of tricalcium silicate,” Cem. Concr. Res. 40, 875-884.

Buhrke, V. E., Jenkins, R., and Smith, D. K. (Eds.) (1998). A practical guide for the preparation of specimens for X-ray fluorescence and X-ray diffraction Analysis (Wiley, New York).

Cromer, D. T. and Liberman, D. A. (1981). “Anomalous dispersion calculations near to an on the long-wavelength side of an absorption edge,” Acta Cryst. A37, 267268.

Delhez, R. and Mittemeijer, E. J. (1975). “An improved $\alpha 2$ elimination,” J. Appl. Cryst., 8, 609-611.

De la Torre, A. G. and Aranda, M. A. G. (2003). “Accuracy in Rietveld quantitative phase analysis of portland cements,” J. Appl. Cryst. 36, 1169-1176.

De la Torre, A. G., Bruque, S., Campo, J. and Aranda, M. A. G. (2002). "The superstructure of $\mathrm{C}_{3} \mathrm{~S}$ from synchrotron and neutron powder diffraction and its role in quantitative phase analyses,” Cem. Concr. Res. 32, 1347-1356.

De la Torre, A. G., De Vera, R. N., Cuberos, A. J. M. and Aranda, M. A. G. (2008). "Crystal structure of low magnesium-content alite: application to Rietveld quantitative phase analysis,” Cem. Concr. Res. 38, 1261-1269.

De la Torre, A. G, Lopez-Olmo, M. G., Alvarez-Rua, C., Garcia-Granda, S. and Aranda, M. A. G. (2004). "Structure and microstructure of gypsum and its relevance to Rietveld quantitative phase analyses,” Powder Diffr., 19, 240-246. 
Dinnebier, R. E. and Billinge, S. J. L. (Eds.) (2008). Powder Diffraction: Theory and Practice (Royal Society of Chemistry, Cambridge).

Dollase W. A. (1986). "Correction of intensities for preferred orientation in powder diffractometry: application of the March model,” J. Appl. Crystallogr. 19, 267272.

Dunstetter, F., De Noirfontaine, M.-N. and Courtial. M. (2006). "Polymorphism of tricalcium silicate, the major compound of Portland cement clinker: 1 . Structural data: review and unified análisis,” Cem. Concr. Res. 36, 39-53.

Elton, N. J. and Salt, P. D. (1996). "Particle statistics in quantitative X-ray diffractometry,” Powder Diffr., 11, 218-229.

Finger, L. W., Cox, D. E. and Jephcoat, A. P. (1994). “A correction for powder diffraction peak asymmetry due to axial divergente,” J. Appl. Cryst. 27, 892900.

García-Maté, M., Santacruz, I., De la Torre, A. G., León-Reina, L. and Aranda, M. A. G. (2012). "Rheological and hydration characterization of calcium sulfoaluminate cement pastes,” Cem. Concr. Comp. 34, 684-691.

Hill, R. J., and Madsen I.C. (2002) in Structure Determination from Powder Diffraction Data, W. David, K. Shankland, L. McCusker and C. Baerlocher (Eds.), Oxford University Press, New York.

Klug, H. P. and Alexander, L. E. (1974). X-ray Diffraction Procedures for Polycrystalline and Amorphous Materials (Wiley, New York), 2nd ed., p. 618.

Knapp, M., Peral, I., Nikitina, L., Quispe, M. and Ferrer, S. (2011). “Technical concept of the materials science beamline at ALBA,” Z. Kristallogr. Proc. 1, 137-142. 
Larson, A. C. and Von Dreele, R. B. (2004). General Structure Analysis System (GSAS) (Report LAUR 86-748). Los Alamos, New Mexico: Los Alamos National Laboratory.

León-Reina, L., De la Torre, A. G., Porras-Vázquez, J. M., Cruz, M., Ordonez, L. M., Alcobé, X., Gispert-Guirado, F., Larrañaga-Varga, A., Paul, M., Fuellmann, T., Schmidt R. and Aranda, M. A. G. (2009). "Round Robin on Rietveld quantitative phase analysis of Portland cements,” J. Appl.Cryst. 42, 906-916.

León-Reina, L., Compana, J. M., De la Torre, A. G., Moreno, R., Ochando, L. E. and Aranda, M. A. G (2011). "Powder diffraction analysis of gemstone inclusions," Powder Diffr., 26(1), 48-52.

Le Saout, G., Kocaba, V. and Scrivener, K. (2011). “Application to the Rietveld method to the analysis of anhydrous cement,” Cem. Concr. Res. 41, 133-148.

Madsen, I. C., Scarlett, N. V. Y., Cranswick, L. M. D. and Lwin, T. (2001). “Outcomes of the International Union of Crystallography Commission on powder diffraction Round Robin on quantitative phase analysis: samples 1a to 1h,” $J$. Appl. Cryst. 34, 409-426.

Mitchell, L. D., Margeson, J. C., and Whitfield, P. S. (2006). “Quantitative Rietveld analysis of hydrated cementitious systems,” Powder Diffr. 21, 111-113.

Rachinger, W. A. (1948). "A correction for the $\alpha 1$ : $\alpha 2$ doublet in the measurement of widths of X-ray diffraction lines," J. Sci. Instrum., 25, 254-259.

Rajczyk, K. and Nocun-Wczelik, W. (1992). “Thermal methods and microcalorimetry application in the studies of low energy cements,” J. Therm. Anal. Calorim. 38, 771-775. 
Scarlett, N. V. Y., Madsen, I. C., Cranswick, L. M. D., Lwin, T., Groleau, E., Stephenson, G., Aylmore, M. and Agron-Olshina, N., (2002). "Outcomes of the International Union of Crystallography Commission on Powder Diffraction Round Robin on Quantitative Phase Analysis: samples 2, 3, 4, synthetic bauxite, natural granodiorite and pharmaceuticals,” J. Appl. Cryst. 35, 383-400.

Scrivener, K. L., Fullmann, T., Gallucci, E., Walenta, G. and Bermejo, E. (2004). “Quantitative study of Portland cement hydration by X-ray diffraction/Rietveld analysis and independent methods,” Cem. Concr. Res. 34 1541-1547.

Scrivener, K. L., and Nonat, A. (2011). "Hydration of cementitious materials, present and future," Cem. Concr. Res. 41 651-665.

Smith, D. K. (2001). "Particle statistics and whole-pattern methods in quantitative X-ray powder diffraction analysis,” Powder Diffr., 16, 186-191.

Stutzman, P. (2005). "Powder diffraction analysis of hydraulic cements: ASTM Rietveld round-robin results on precision,” Powder Diffr., 20, 97-100.

Thompson, P., Cox, D. E. and Hasting, J. B. (1987). "Rietveld refinement of DebyeScherrer synchrotron X-ray data from $\mathrm{Al}_{2} \mathrm{O}_{3}$,” J. Appl. Cryst. 20, 79-83. 
Tables

Table I. Transmission laboratory X-ray powder diffraction experimental setups with flat samples.

\begin{tabular}{|c|c|c|c|}
\hline & Mo $K \alpha_{1}-\mathrm{D} 8$ & Mo $K \alpha_{1,2}$-EMPYREAN & Cu $K \alpha_{1,2}$-EMPYREAN \\
\hline X-ray tube & Ceramic Mo - long fine focus & Ceramic Mo - long fine focus & Ceramic $\mathrm{Cu}$ - long fine focus \\
\hline$\lambda(\AA ̊)$ & 0.70932 & 0.7107 & 1.5418 \\
\hline Applied power & $50 \mathrm{kV}, 45 \mathrm{~mA}$ & $60 \mathrm{kV}, 40 \mathrm{~mA}$ & $45 \mathrm{kV}, 40 \mathrm{~mA}$ \\
\hline Tube focus & Long line & Line & Line \\
\hline Flat sample stage & transmission spinner (10 rpm) & transmission spinner (60 rpm) & transmission spinner (15 rpm) \\
\hline \multicolumn{4}{|c|}{ Incident beam optics } \\
\hline Optic device & $\begin{array}{l}\text { Johansson monochromator } \\
\text { Ge (220) }\end{array}$ & $\begin{array}{l}\text { Focusing X-ray mirror for Mo } \\
\text { radiation }\end{array}$ & $\begin{array}{l}\text { Focusing } \mathrm{X} \text {-ray mirror for } \mathrm{Cu} \\
\text { radiation }\end{array}$ \\
\hline Beam width ( $\left.B_{w}\right)$ & $16 \mathrm{~mm}$ & $20 \mathrm{~mm}$ & $12.9 \mathrm{~mm}$ \\
\hline Soller slit & $1.6^{\circ}(0.028 \mathrm{rad})$ & $0.02 \mathrm{rad}$ & $0.04 \mathrm{rad}$ \\
\hline Divergence slit $\left(\mathrm{S}_{\mathrm{w}}\right)$ & $2 \mathrm{~mm}$ & $0.7 \mathrm{~mm}$ & $0.7 \mathrm{~mm}$ \\
\hline Anti-Scatter slit & -- & $1 / 4^{0}$ & $1 / 2^{0}$ \\
\hline \multicolumn{4}{|c|}{ Diffracted beam optics } \\
\hline Anti-Scatter slit & -- & $2 \mathrm{~mm}$ & $5 \mathrm{~mm}$ \\
\hline Soller slit & $1.6^{\circ}(0.028 \mathrm{rad})$ & $0.02 \mathrm{rad}$ & $0.04 \mathrm{rad}$ \\
\hline Detector & $\begin{array}{l}\text { LYNXEYE XE } 500 \mu \mathrm{m} \\
\left(3.5^{\circ} \text { opening }\right)\end{array}$ & $\begin{array}{l}\text { X'CELERATOR (scanning } \\
\text { mode } 2.122^{\circ} \text { active length) }\end{array}$ & $\begin{array}{l}\text { PIXCEL 3D RTMS (scanning } \\
\text { mode } 3.347^{\circ} \text { active length) }\end{array}$ \\
\hline
\end{tabular}


Table II. Data acquisition details for LXRPD patterns collected using $\mathrm{Mo}$ and $\mathrm{Cu}$ radiations in transmission $(\mathrm{t})$ and reflection geometries $(\mathrm{r})$.

\begin{tabular}{|c|c|c|c|}
\hline & $\begin{array}{c}\text { Angular range } \\
\left({ }^{\circ}\right)\end{array}$ & $\begin{array}{c}\text { step size } \\
\left({ }^{\circ}\right)\end{array}$ & $\begin{array}{c}\text { Average total } \\
\text { time (min) }\end{array}$ \\
\hline D8 $\left(\right.$ Mo $\left.K \alpha_{1}\right)(\mathrm{t})$ & $3-30$ & 0.009 & 150 \\
\hline EMPYREAN (Mo $K \alpha_{2 \text {-strip }}$ (t) & $3-31$ & 0.017 & 100 \\
\hline EMPYREAN (Cu $\left.K \alpha_{1,2}\right)(\mathrm{t})$ & $5-70$ & 0.013 & 170 \\
\hline X'PERT (Cu K $\left.K \alpha_{1}\right)(\mathbf{r})$ & $5-70$ & 0.013 & 120 \\
\hline
\end{tabular}

Table III. Density $(\rho)$, linear absorption coefficient $(\mu)$, fractional attenuation factor of the beam due to absorption (a.f.) and thickness (t) of flat samples for transmission LXRPD measurements.

\begin{tabular}{cccccc}
\hline Sample & $\begin{array}{c}\boldsymbol{\rho} \\
\left(\mathbf{g} / \mathbf{c m}^{\mathbf{3}}\right)\end{array}$ & & Mo $\boldsymbol{K} \boldsymbol{\alpha}_{\mathbf{1}}$ & Mo $\boldsymbol{K} \boldsymbol{\alpha}_{\text {2-strip }}$ & $\mathbf{C u} \boldsymbol{K} \boldsymbol{\alpha}_{\mathbf{1 , 2}}$ \\
\hline \multirow{2}{*}{ 25G_CSA } & \multirow{2}{*}{2.7} & $\mu\left(\mathrm{cm}^{-1}\right)$ & 24 & 24 & 205 \\
& & a.f. & 2.5 & 2.7 & 3.0 \\
& & $\mathrm{t}(\mathrm{mm})^{*}$ & 0.5 & 0.5 & 0.07 \\
\hline \multirow{2}{*}{ GP_Clin } & \multirow{2}{*}{3.3} & $\mu\left(\mathrm{cm}^{-1}\right)$ & 36 & 36 & 320 \\
& & a.f. & 2.2 & 2.1 & 2.9 \\
& & $\mathrm{t}\left(\mathrm{mm}^{*}\right.$ & 0.3 & 0.3 & 0.04 \\
\multirow{2}{*}{ GP_Cem } & \multirow{2}{*}{3.2} & $\mu\left(\mathrm{cm}^{-1}\right)$ & 35 & 35 & 307 \\
& & a.f. & 2.2 & 2.5 & 2.7 \\
\hline
\end{tabular}

$* 75 \%$ packing factor is assumed 
Table IV. Comparative of the RQPAs for sample 25G_CSA measured with different radiations (Mo, Cu and Synchrotron) and geometries

\begin{tabular}{|c|c|c|c|c|c|c|c|c|c|}
\hline Phase (wt\%) & $\begin{array}{c}\text { Comments } \\
\text { DTA-TG } \\
\text { wt } \% \\
\end{array}$ & $\begin{array}{c}\text { Synchr } \\
\lambda=0.62 \AA \\
\text { t-capillary }\end{array}$ & $\begin{array}{c}\text { Mo } K \alpha_{1} \\
\text { t-flat }\end{array}$ & $\begin{array}{c}\text { Mo } K \boldsymbol{\alpha}_{2 \text {-strip }} \\
\text { t-flat }\end{array}$ & $\begin{array}{c}\text { Cu } K \alpha_{1} \\
\text { r-flat }\end{array}$ & $\begin{array}{c}\mathrm{Cu} K \boldsymbol{\alpha}_{1,2} \\
\text { t-flat }\end{array}$ & $\begin{array}{c}\boldsymbol{\mu} \\
{[\mathrm{CuK \alpha}]} \\
\left(\mathrm{cm}^{-1}\right)\end{array}$ & $\begin{array}{c}\boldsymbol{\mu} \\
{[\mathrm{Mo} \mathrm{K \alpha}]} \\
\left(\mathrm{cm}^{-1}\right)\end{array}$ & $\begin{array}{c}\boldsymbol{\mu} \\
{[\lambda=0.62 \AA]} \\
\left(\mathrm{cm}^{-1}\right)\end{array}$ \\
\hline $\mathrm{C}_{4} \mathrm{~A}_{3} \underline{\mathrm{S}}$ & & $51.7(1)$ & $47.5(2)$ & $51.5(2)$ & $47.9(1)$ & $50.6(1) / 51.1(1)^{*}$ & 171 & 19 & 13 \\
\hline$\beta-C_{2} S$ & & 12.7(3) & 17.1(5) & $11.5(7)$ & $11.0(3)$ & $11.0(5) / 10.5(5)^{*}$ & 299 & 34 & 23 \\
\hline $\mathrm{C}_{4} \mathrm{AF}$ & & $1.2(1)$ & - & - & $0.7(1)$ & - & 388 & 58 & 39 \\
\hline CT & & $6.4(1)$ & $6.4(2)$ & $7.1(3)$ & $6.8(2)$ & $7.6(2) / 7.5(2)^{*}$ & 485 & 57 & 38 \\
\hline MgO & & $1.9(1)$ & $1.5(1)$ & $1.8(2)$ & $1.4(1)$ & $1.0(1) / 0.9(1)^{*}$ & 100 & 10 & 7 \\
\hline $\mathrm{Ca}_{2} \mathrm{MgSi}_{2} \mathrm{O}_{7}$ & & - & - & $1.3(2)$ & $1.4(1)$ & $1.1(2) / 1.1(2)^{*}$ & 204 & 23 & 15 \\
\hline $\begin{array}{l}\mathrm{CaSO}_{4} \cdot 2 \mathrm{H}_{2} \mathrm{O} \\
\left(\mathrm{CSSH}_{2}\right)\end{array}$ & 24.96 & $26.1(2)$ & 27.6(3) & $26.8(3)$ & $31.0(1)$ & $28.7(2) / 28.9(2)^{*}$ & 140 & 16 & 11 \\
\hline $\begin{array}{l}\text { P.O.C. } \mathbf{C S H}_{2}\left[\begin{array}{ll}0 & 1 \\
0\end{array}\right]\end{array}$ & & 1.00 & $1.180(7)$ & $1.085(8)$ & $0.732(2)$ & $1.300(7) / 1.290(7)^{*}$ & & & \\
\hline
\end{tabular}

${ }^{*}$ Rietveld quantitative phase analysis obtained after the application of the correction factor due to not preserving constant volume assumption. 
Table V. Comparative of the RQPAs for sample GP_Clin measured with synchrotron, Mo and Cu radiations, as in Table IV.

\begin{tabular}{|c|c|c|c|c|c|c|c|c|}
\hline Phase (wt\%) & ${ }^{\$}$ R.R. & $\begin{array}{c}\text { Synchr } \\
\lambda=0.62 \AA \\
\text { t-capillary }\end{array}$ & $\begin{array}{c}\text { Mo } K \alpha_{1} \\
\text { t-flat }\end{array}$ & $\begin{array}{c}\text { Mo } K \boldsymbol{\alpha}_{2 \text {-strip }} \\
\text { t-flat }\end{array}$ & $\begin{array}{c}\text { Cu } K \alpha_{1,2} \\
\text { t-flat }\end{array}$ & $\begin{array}{c}\boldsymbol{\mu} \\
{[\mathrm{Cu} K \alpha]} \\
\left(\mathrm{cm}^{-1}\right)\end{array}$ & $\begin{array}{c}\boldsymbol{\mu} \\
{\left[\mathrm{Mo} \mathrm{K \alpha}^{-1}\right]} \\
\left(\mathrm{cm}^{-1}\right)\end{array}$ & $\begin{array}{c}\boldsymbol{\mu} \\
{[\lambda=0.62 \AA]} \\
\left(\mathrm{cm}^{-1}\right)\end{array}$ \\
\hline $\mathrm{C}_{3} \mathrm{~S}$ & $\begin{array}{c}66.6(2 . \\
8)\end{array}$ & 63.1(1) & $62.7(3)$ & $62.1(1)$ & $56.5(2) / 56.2(2)^{*}$ & 313 & 36 & 24 \\
\hline $\mathrm{C}_{2} \mathrm{~S}$ & $\begin{array}{c}19.2(2 . \\
5)\end{array}$ & $20.0(3)$ & 21.9(4) & 21.7(4) & $26.3(5) / 26.7(5)^{*}$ & 299 & 34 & 23 \\
\hline $\mathbf{C}_{3} \mathrm{~A}$ & $2.4(0.5)$ & $3.1(2)$ & $2.3(2)$ & $2.7(2)$ & $2.4(2)\left(2.3(2)^{*}\right.$ & 260 & 30 & 20 \\
\hline $\mathrm{C}_{4} \mathrm{AF}$ & $9.9(1.2)$ & 12.1(3) & $11.7(2)$ & $11.9(2)$ & $13.6(2) / 13.7(3)^{*}$ & 388 & 33 & 22 \\
\hline $\mathrm{NaK}_{3}\left(\mathrm{SO}_{4}\right)_{2}$ & $0.8(0.2)$ & $0.6(1)$ & $0.7(1)$ & $0.7(1)$ & $0.6(1) / 0.5(1)^{*}$ & 195 & 22 & 15 \\
\hline MgO & $1.0(0.2)$ & $1.0(1)$ & $0.9(1)$ & $0.9(1)$ & $0.6(1) / 0.5(1)^{*}$ & 100 & 10 & 7 \\
\hline P.O.C. $\mathbf{C}_{3} \mathbf{S}\left[\begin{array}{lll}1 & 0 & -1\end{array}\right]$ & & $1.0(-)$ & $1.020(3)$ & $1.034(4)$ & $1.040(4) / 1.040(4)^{*}$ & & & \\
\hline
\end{tabular}

$\$$ Mean and standard deviation values from the Round Robin study (León-Reina et al., 2009). In this case, the average values and the standard deviations were derived from the results of the fourteen participants.

* Rietveld quantitative phase analysis obtained after the application of the correction factor due to not preserving constant volume assumption. 
Table VI. Comparative of the RQPAs for sample GP_Cem measured with Cu, Mo and synchrotron radiations, as in Table IV

\begin{tabular}{|c|c|c|c|c|c|c|c|c|c|}
\hline Phase (wt \%) & $* \mathbf{R} . \mathbf{R}$. & $\begin{array}{c}\text { Comments } \\
\text { DTA-TG } \\
\text { wt\% }\end{array}$ & $\begin{array}{c}\text { Synchr } \\
\lambda=0.62 \AA\end{array}$ & Mo $K \alpha_{1}$ & Mo $K \boldsymbol{\alpha}_{2 \text {-strip }}$ & $\operatorname{Cu} K \alpha_{1,2}$ & $\begin{array}{c}\boldsymbol{\mu} \\
{[\mathrm{Cu} K \alpha]} \\
\left(\mathrm{cm}^{-1}\right)\end{array}$ & $\begin{array}{c}\boldsymbol{\mu} \\
{\left[\mathrm{Mo} \mathrm{K \alpha}^{-} \mathrm{K}\right]} \\
\left(\mathrm{cm}^{-1}\right)\end{array}$ & $\begin{array}{c}\boldsymbol{\mu} \\
{[\lambda=0.62 \AA]} \\
\left(\mathrm{cm}^{-1}\right)\end{array}$ \\
\hline $\mathrm{C}_{3} \mathrm{~S}$ & $62.0(3.2)$ & & $61.6(1)$ & $64.8(1)$ & $64.6(1)$ & $55.8(2)$ & 313 & 36 & 24 \\
\hline $\mathrm{C}_{2} \mathrm{~S}$ & $9.9(2.8)$ & & $7.7(4)$ & $7.1(4)$ & $8.1(5)$ & $13.9(9)$ & 299 & 34 & 23 \\
\hline $\mathrm{C}_{3} \mathrm{~A}$ & $4.8(1.2)$ & & $5.2(2)$ & $5.0(2)$ & $4.9(2)$ & $4.9(2)$ & 260 & 30 & 20 \\
\hline $\mathrm{C}_{4} \mathrm{AF}$ & $10.0(1.0)$ & & $12.5(2)$ & $9.9(2)$ & $10.8(2)$ & $10.5(3)$ & 388 & 33 & 22 \\
\hline $\mathrm{NaK}_{3}\left(\mathrm{SO}_{4}\right)_{2}$ & $1.4(0.4)$ & & $0.7(1)$ & $0.7(1)$ & $0.8(1)$ & $0.8(1)$ & 195 & 22 & 15 \\
\hline $\mathrm{CaSO}_{4} \cdot 2 \mathrm{H}_{2} \mathrm{O}\left(\mathrm{CSH}_{2}\right)$ & $1.5(0.5)$ & 1.45 & $1.3(2)$ & $1.6(1)$ & $1.3(1)$ & $2.0(1)$ & 140 & 16 & 11 \\
\hline $\mathrm{CaSO}_{4} \cdot 1 / 2 \mathrm{H}_{2} \mathrm{O}$ & $2.4(0.7)$ & 2.67 & $1.4(1)$ & $1.6(1)$ & $1.7(1)$ & $2.7(1)$ & 191 & 22 & 14 \\
\hline $\mathrm{CaCO}_{3}$ & $5.6(1.9)$ & 7.03 & $8.7(1)$ & 8.1(1) & $6.7(1)$ & $8.5(2)$ & 193 & 22 & 15 \\
\hline MgO & $1.8(0.5)$ & & $0.8(1)$ & $1.1(1)$ & $1.2(1)$ & $0.9(1)$ & 100 & 10 & 7 \\
\hline P.O.C. $\mathbf{C}_{3}$ S $\left[\begin{array}{lll}1 & 0 & -1\end{array}\right]$ & & & $1.050(4)$ & $1.020(4)$ & $1.027(4)$ & $1.020(5)$ & & & \\
\hline P.O.C. $\mathbf{C S H}_{2}\left[\begin{array}{lll}0 & 1 & 0\end{array}\right]$ & & & $1.00(-)$ & $1.00(-)$ & $1.00(-)$ & $1.00(-)$ & & & \\
\hline $\begin{array}{l}\text { P.O.C. } \mathrm{CaCO}_{3}\left[\begin{array}{ll}1 & 0 \\
4\end{array}\right]\end{array}$ & & & $1.00(-)$ & $1.00(-)$ & $1.00(-)$ & $0.71(1)$ & & & \\
\hline
\end{tabular}

Mean and standard deviation values from the Round Robin study (León-Reina et al., 2009). In this case, the average values and the standard deviations were derived from the results of the fourteen participants. 
Table VII. Comparative of the RQPA results (wt\%) for hydrated samples measured with Mo $K \alpha_{1}$ and synchrotron radiations.

\begin{tabular}{|c|c|c|c|c|c|c|}
\hline & \multicolumn{2}{|c|}{ G10B0 } & \multicolumn{2}{|c|}{ G5B2 } & \multicolumn{2}{|c|}{ G10B2 } \\
\hline Phase (wt\%) & Mo $K \alpha_{1}$ & $\begin{array}{c}\text { Synchr } \\
\lambda=0.62 \AA\end{array}$ & Mo $K \alpha_{1}$ & $\begin{array}{c}\text { Synchr } \\
\lambda=0.62 \AA\end{array}$ & Mo $K \alpha_{1}$ & $\begin{array}{c}\text { Synchr } \\
\lambda=0.62 \AA\end{array}$ \\
\hline$\alpha^{\prime}{ }_{\mathrm{H}}-\mathrm{C}_{2} \mathrm{~S}^{*}$ & - & - & $36.4(3)$ & $30.2(2)$ & 33.3(4) & $30.7(2)$ \\
\hline$\beta-C_{2} S^{*}$ & $20.9(4)$ & $22.8(2)$ & & & - & - \\
\hline$\gamma-C_{2} S^{*}$ & $2.4(1)$ & $2.3(1)$ & & & - & - \\
\hline $\mathrm{C}_{2} \mathrm{AS}^{*}$ & $4.0(1)$ & $2.9(1)$ & $1.9(1)$ & $1.6(2)$ & $1.6(1)$ & $1.8(2)$ \\
\hline CT* & - & - & $1.3(1)$ & $1.1(1)$ & $1.3(1)$ & $1.0(1)$ \\
\hline Ettringite $^{\#}$ & $12.4(2)$ & $16.6(2)$ & 10.1(3) & $7.8(2)$ & $19.5(2)$ & 20.3(3) \\
\hline Stratlingite & $38.7(5)$ & $35.7(3)$ & 21.8(4) & $22.0(3)$ & 13.1(5) & $10.2(4)$ \\
\hline Katoite $^{\#}$ & $12.7(3)$ & $13.0(2)$ & $21.5(3)$ & $24.1(2)$ & $19.5(1)$ & 20.5(3) \\
\hline Vaterite $^{\#}$ & $6.4(2)$ & $4.2(2)$ & $6.5(2)$ & 13.2(3) & $9.7(2)$ & 13.7(3) \\
\hline Calcite $^{\#}$ & $2.5(1)$ & $2.4(1)$ & $0.5(1)$ & - & $2.0(2)$ & $1.8(1)$ \\
\hline
\end{tabular}

* Phase from the anhydrous cement.

\# Phase resulting from the hydration reactions. 
Figure 1. Full width at the half maximum evolution with diffracting angle for all diffractometers and configurations used in this study.

Figure 2. Irradiated volume for flat sample holder in transmission mode using (a) molybdenum radiation and (b) copper radiation; and (c) reflection mode using copper radiation. Diffraction geometry sketches (d) transmission geometry with primary monochromator, (e) transmission geometry with focusing mirror and (f) reflection geometry with primary monochromator.

Figure 3. Raw (red) and corrected (black) data for 25G_CSA. Inset shows the applied correction factors considering the improvement of irradiated volume and absorption.

Figure 4. Rietveld plots for GP_Cem collected in transmission mode with flat sample with (a)

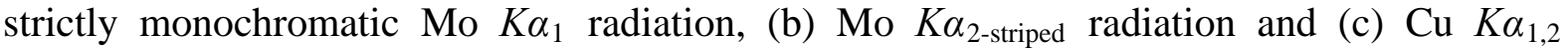
radiations.

Figure 5. Rietveld plots for G10B0 hydrated sample patterns (a) strictly monochromatic Mo $K \alpha_{1}$ radiation in transmission with flat sample, (b) synchrotron radiation in transmission with sample in a capillary. 


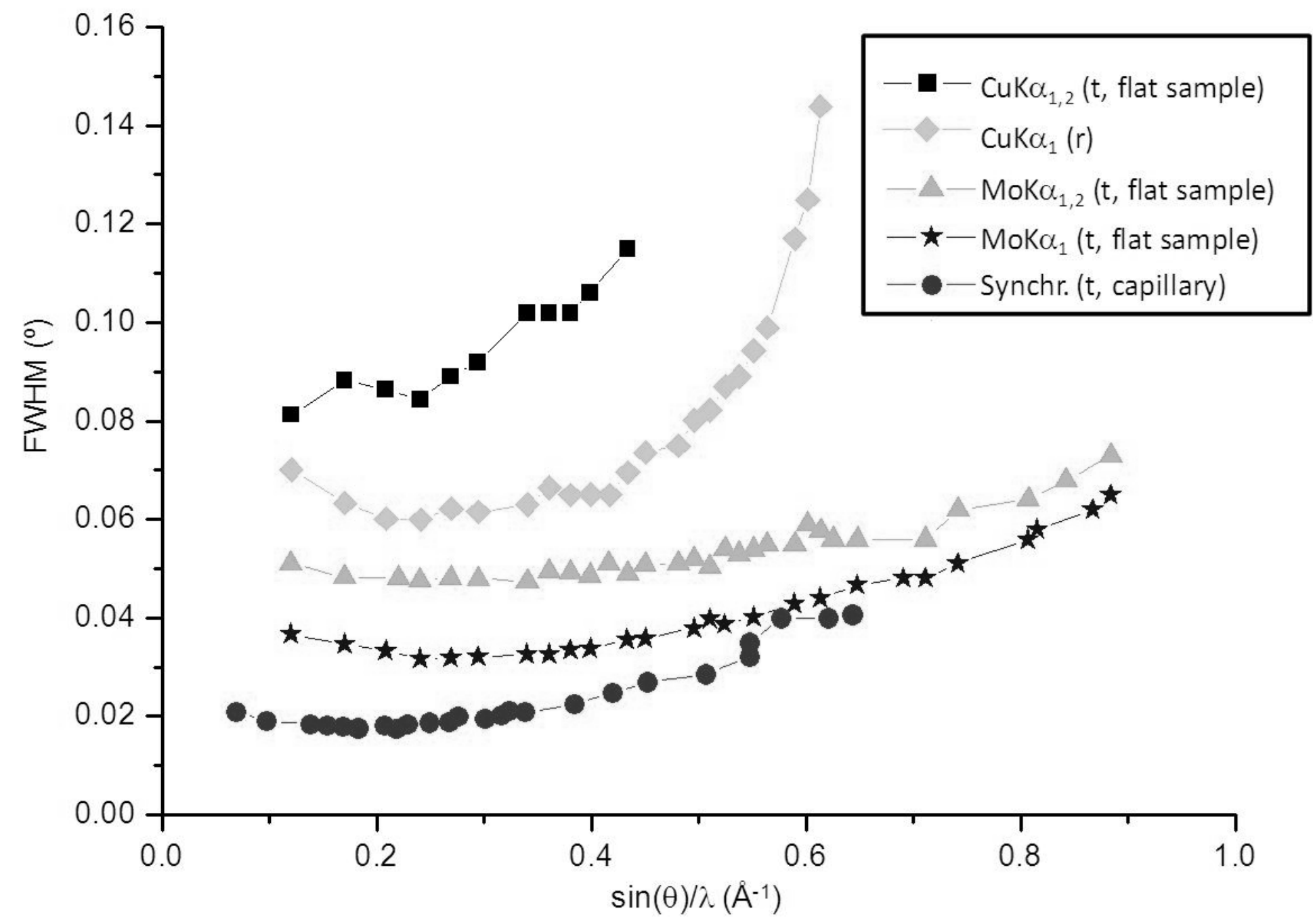

Figure 1 


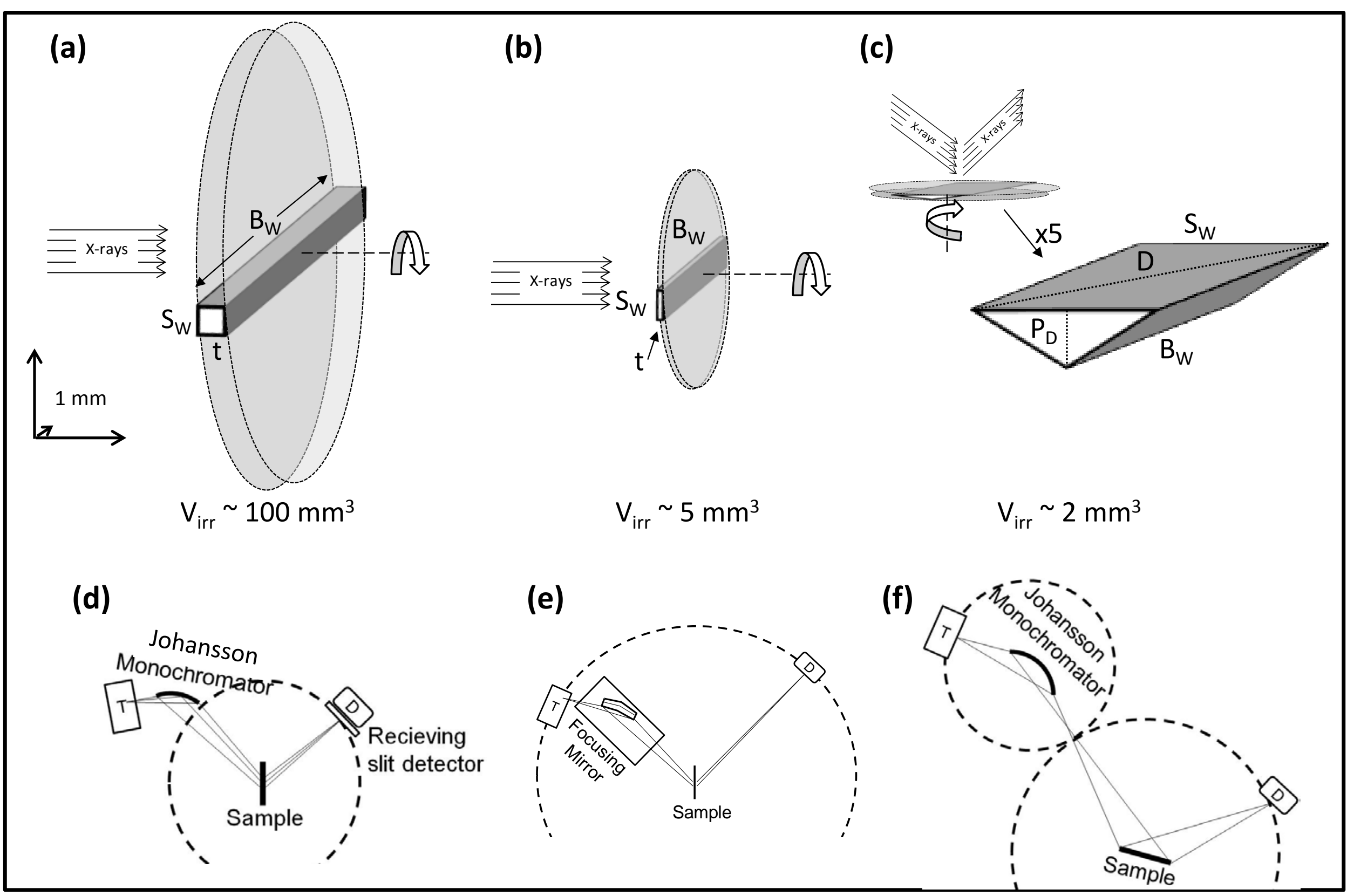

Figure 2 


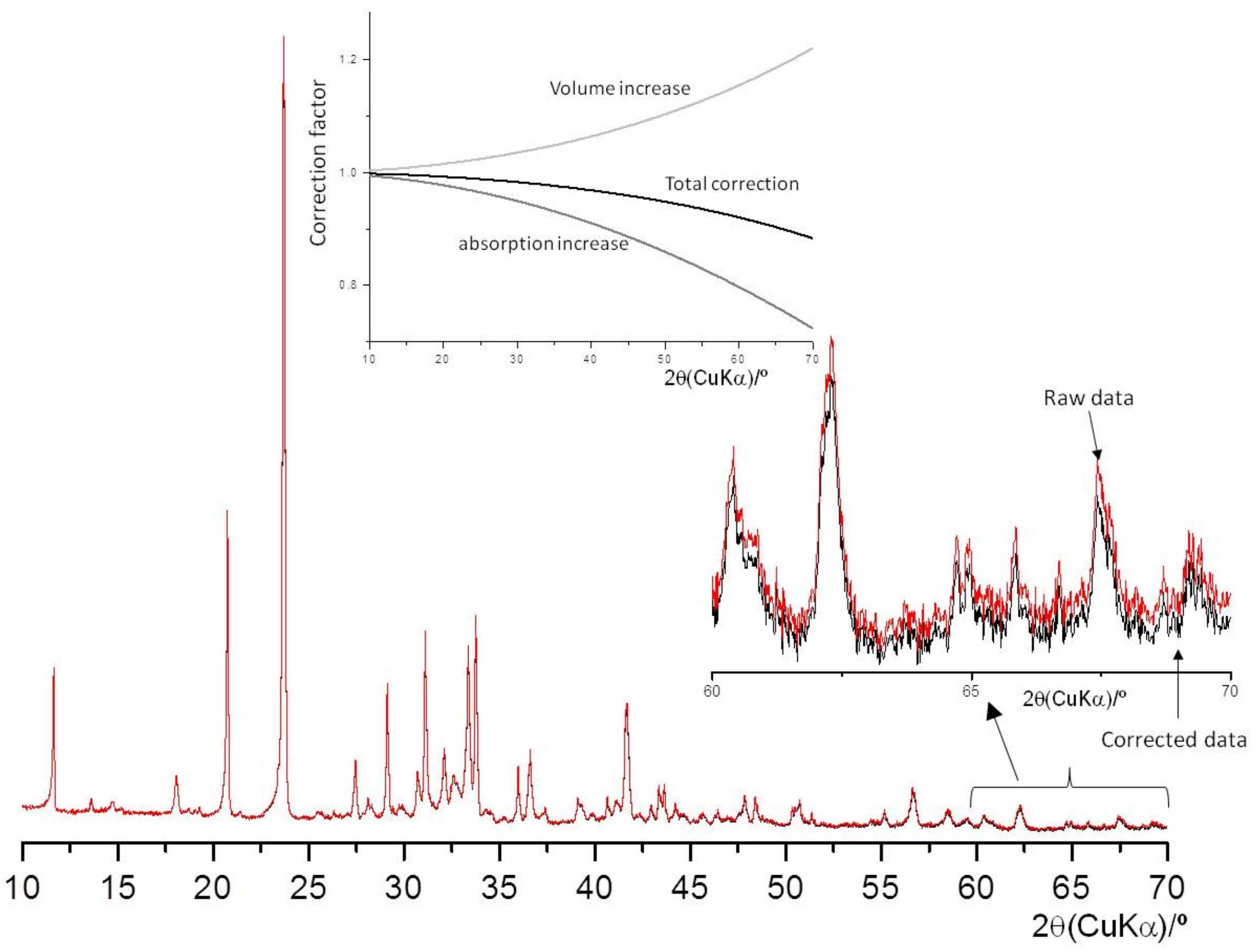

Figure 3 

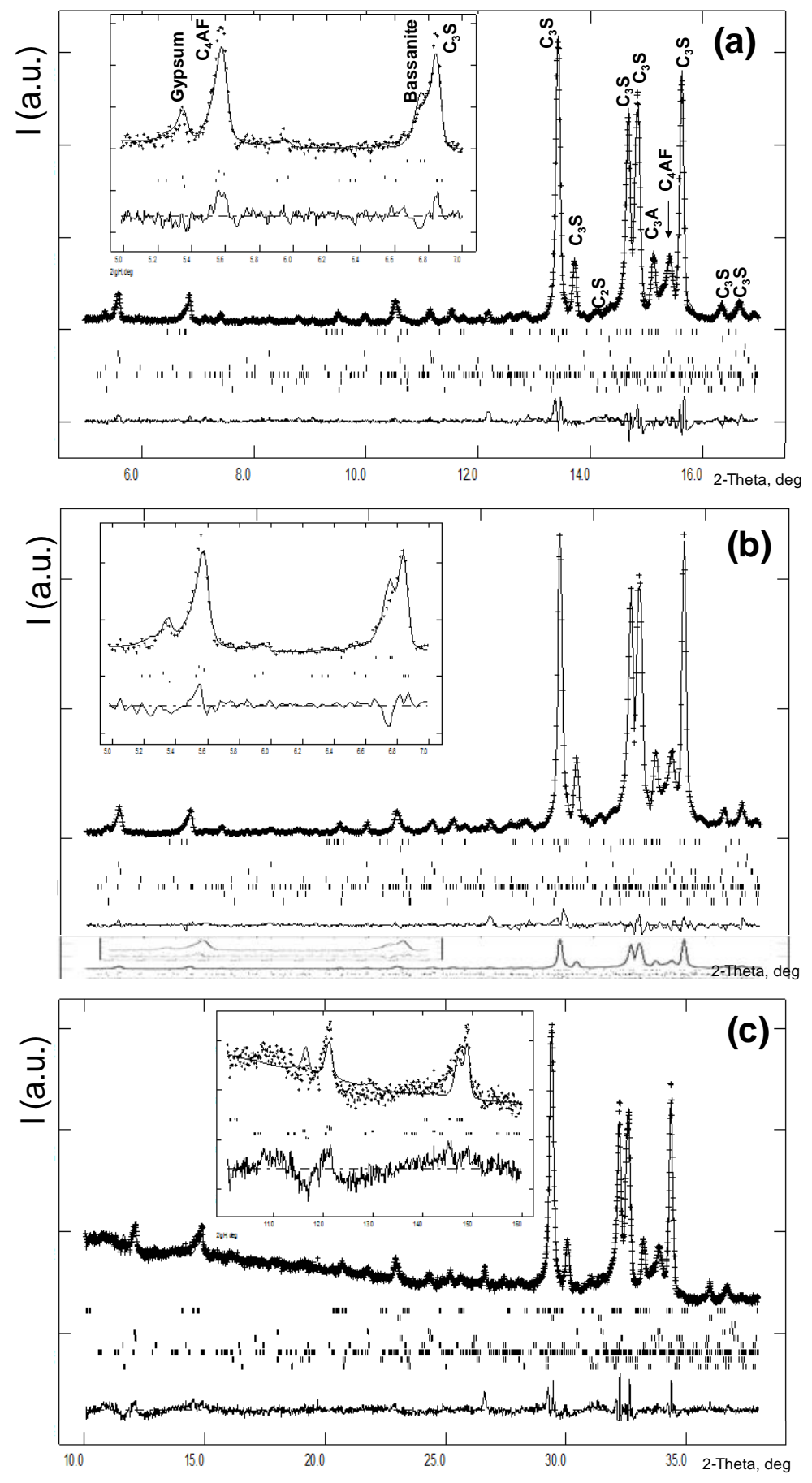

Figure 4 


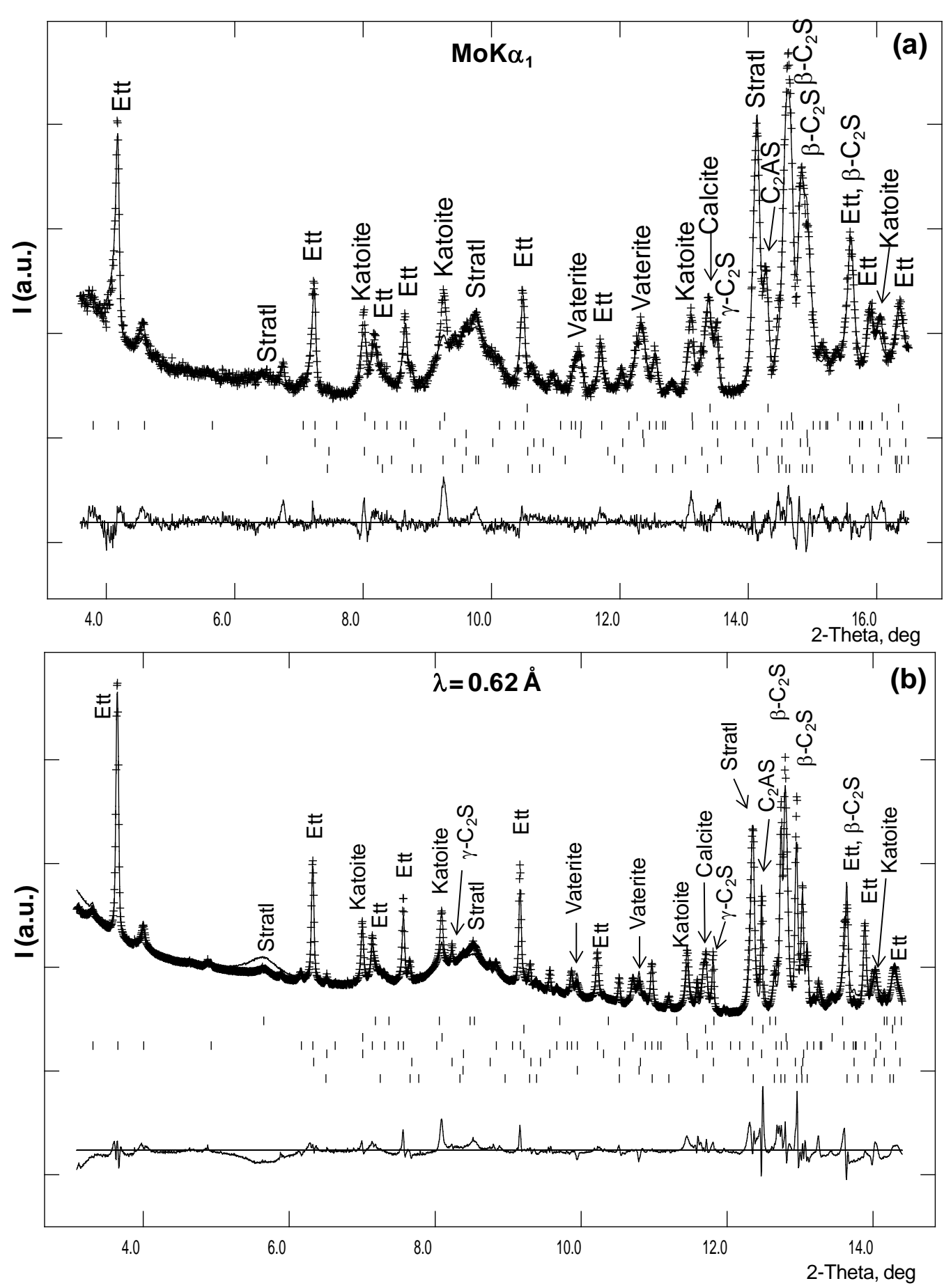

Figure 5 